\title{
PARTIAL SUMS OF MITTAG-LEFFLER FUNCTION
}

\section{DEEPAK BANSAL AND HALIT ORHAN}

Abstract. In the present investigation, Mittag-Leffler function with their normalization are considered. In this paper, we will study the ratio of a function of the form (??) to its sequence of partial sums $\left(\mathbb{E}_{\lambda, \mu}\right)_{n}(z)=z+\sum_{k=1}^{n} \frac{\Gamma(\mu)}{\Gamma(\lambda k+\mu)} z^{k+1}$. We will determine lower bounds for $\Re\left\{\frac{\mathbb{E}_{\lambda, \mu}(z)}{\left(\mathbb{E}_{\lambda, \mu}\right)_{n}(z)}\right\}$, $\Re\left\{\frac{\left(\mathbb{E}_{\lambda, \mu}\right)_{n}(z)}{\mathbb{E}_{\lambda, \mu}(z)}\right\}, \Re\left\{\frac{\mathbb{E}_{\lambda, \mu}^{\prime}(z)}{\left(\mathbb{E}_{\lambda, \mu}^{\prime}\right)_{n}(z)}\right\}$ and $\Re\left\{\frac{\left(\mathbb{E}_{\lambda, \mu}^{\prime}\right)_{n}(z)}{\mathbb{E}_{\lambda, \mu}^{\prime}(z)}\right\}$. Results obtained are new and their usefulness are depicted by deducing several interesting examples.

Mathematics subject classification (2010): 33E12, 30C45.

Keywords and phrases: Mittag-Leffler function, analytic function, univalent, subordination.

\section{REFERENCES}

[1] D. Bansal and J. K. PrajaPat, Certain geometric properties of the Mittag-Leffler functions, Complex Var. Elliptic Eq. 61 (3) (2016), 338-350.

[2] Á. BARICZ AND S. PoONUSAMY, Starlikeness and convexity of generalized Bessel functions, Integral Transform. Spec. Funct. 21 (9) (2010), 641-653.

[3] Á. BARICZ, Generalized Bessel Functions of the First Kind, Lecture Notes in Mathematics: Vol. 1994: Springer-Verlag, Berlin, 2010.

[4] Á. BARICZ, P. A. KuPÁN, AND R. SZÁsZ, The radius of starlikeness of normalized Bessel function of first kind, Proc. Amer. Math. Soc. 142 (6) (2014), 2019-2025.

[5] Á. BARICZ AND R. SZÁsZ, The radius of convexity of normalized Bessel functions of the first kind, Anal. Appl. 12 (5) (2014), 485-509.

[6] M. M. DZherbashyan, Integral Transforms and Representations of Functions in the Complex Plane, Nauka, Moscow, 1966 (in Russian).

[7] R. Hilfer (ed.), Applications of Fractional Calculus in Physics, World Scientific, Singapore, 2000.

[8] K. R. LAnG, Astrophysical Formulae, Vol. 1: Radiation, Gas Processes and High-energy Astrophysics, 3rd edition, Revised edition, Springer-Verlag, New York, 1999a.

[9] K. R. LAng, Astrophysical Formulae, Vol. 2: Space, Time, Matter and Cosmology, Springer-Verlag, New York, 1999b.

[10] S. S. Miller And P. T. Mocanu, Differential Subordinations, Theory and Applications, New YorkBasel, Marcel Dekker, 2000.

[11] S. S. Miller and P. T. Mocanu, Univalence of Gaussian and confluent hypergeometric functions, Proc. Amer. Math. Soc. 110 (2) (1990), 333-342.

[12] G. M. MitTAG-LefFler, Sur la nouvelle fonction $E_{\alpha}(x)$, C. R. Acad. Sci. Paris 137 (1903), 554558.

[13] H. Orhan and N. Yagmur, Partial sums of generalized Bessel functions, J. Math. Inequal. 8 (4) (2014), 863-877.

[14] S. OWa, H. M. SRivastava AND N. Saito, Partial sums of certain classes of analytic functions, Int. J. Comput. Math. 81 (10) (2004), 1239-1256.

[15] S. Ponnus amy, Close-to-convexity properties of Gaussian hypergeometric functions, J. Comput. Appl. Maths. 88 (1997), 327-337.

[16] S. Ponnus Amy AND M. VuORInen, Univalence and convexity properties for Gaussian hypergeometric functions, Rocky Mountain J. Math. 31 (1) (2001), 327-353. 
[17] J. K. Prajapat, Certain geometric properties of normalized Bessel functions, Appl. Math. Letters 24 (2011), 2133-2139.

[18] J. K. Prajapat, Certain geometric properties of the Wright functions, Integral Transform. Spec. Funct. 26 (3) (2015), 203-212.

[19] St. RuscheWEyH AND V. Singh, On the order of starlikeness of hypergeometric functions, J. Math. Anal. Appl. 113 (1986), 1-11.

[20] R. K. Saxena, A. M. Mathai and H. J. Haubold, On fractional kinetic equations, Astrophysics and Space Science 282 (2002), 281-287.

[21] T. Sheil-Small, A note on partial sums of convex schlicht functions, Bull. London Math. Soc. 2 (1970), 165-168.

[22] H. Silverman, Partial sums of starlike and convex functions, J. Math. Anal. Appl. 209 (1997), $221-$ 227.

[23] E. M. Silvia, On partial sums of convex functions of order $\alpha$, Houston J. Math. 11 (1985), 397-404.

[24] A. Wiman, Über den Fundamental satz in der Theorie der Funcktionen, $E_{\alpha}(x)$, Acta Mathematica 29 (1905), 191-201.

[25] A. Wiman, Über die Nullstellun der Funktionen $E_{\alpha}(x)$, Acta Mathematica 29 (1905a), 217-234. 